\title{
Totally Implantable Central Venous Port Catheters: Radiation Exposure as a Function of Puncture Site and Operator Experience
}

\author{
MARTIN JONCZYK ${ }^{1,2}$, BERNHARD GEBAUER ${ }^{1}$, ROMAN ROTZINGER ${ }^{1}$, \\ DIRK SCHNAPAUFF ${ }^{1}$, BERND HAMM $^{1}$ and FEDERICO COLLETTINI ${ }^{1,2}$ \\ ${ }^{1}$ Department of Radiology, Charité - University of Medicine, Berlin, Germany; \\ ${ }^{2}$ Berlin Institute of Health, Berlin, Germany
}

\begin{abstract}
Background: Totally implantable central venous port systems provide a safe and effective, long-term means of access for administration of hyperosmolar, local irritant medication, such as chemotherapy, antibiotics and parenteral nutrition. Aim: To evaluate the combination of access site and level of experience on fluoroscopy times (FT) and dose area products (DAP) during implantation of port catheters in a large patient population. Materials and Methods: A total of 1,870 patients (992 women, 878 men; age: $61 \pm 13.14$ years) were reviewed investigating two groups of junior ( $\leq 50$ implantations) and senior (>50) radiologists. Results: Senior radiologists required less FT/DAP $\left(0.24 \mathrm{~s} / 57.3 \mu G y \mathrm{~m}^{2}\right.$ versus $0.43 \mathrm{~s} / 68.2 \mu G y \mathrm{~m}^{2}$, respectively; $p<0.001)$. Right jugular vein access required the least FT/DAP (0.25 s/56.15 $\left.\mu G y \mathrm{~m}^{2}\right)$ and right-sided


$\left.0.40 \mathrm{~s} / 85.10 \mu G y \mathrm{~m}^{2}, p<0.001\right)$. Conclusion: Due to DAP/FT reductions, the right jugular vein seems to be the most favorable implantation side for port systems. For further dose reduction, residents should be well-trained.
\end{abstract}

Totally implantable central venous port catheters have proven to be a safe and provide effective, long-term means of access for administration of medication. A central venous access is mandatory for hyperosmolar, basic $(\mathrm{pH} \leq 4.0)$, alkaline ( $\mathrm{pH}$ $\geq 9.0$ ) and local irritant medication, such as chemotherapy, antibiotics and parenteral nutrition. Moreover, high pressure

This article is freely accessible online.

Correspondence to: Martin Jonczyk, MD, Charité - Universitätsmedizin Berlin, Department of Radiology, Augustenburger Platz 1, 13353 Berlin, Germany. Tel: +49 30450657178, martin.jonczyk@charite.de

Key Words: Totally implantable central venous port systems, radiation exposure, fluoroscopy time, dose area product, training. infusions such as those required for computed tomographic examinations of up to $5 \mathrm{ml} / \mathrm{s}$, as well as blood tests, which can be performed through such selected systems, streamlining workflow and increasing patient quality of life (1-3).

Introduced by the surgeons Niederhuber et al. in 1982 (4), the first radiological inserted port system was reported a decade later by Morris et al. (5). While the surgical procedure includes either landmark-based puncture of a central vein using Seldinger technique, or a cut-down technique of the cephalic vein, the radiological approach is based on ultrasound-guided vessel puncture and tip positioning under fluoroscopy (3). Moreover, electrocardiogram- (ECG)-guided implantations have been reported (6).

However, surgical approaches using the cephalic and the subclavian vein led to complication rates of between $5 \%$ and $24.6 \%$, whereas radiological placements had lower complication rates, of between $1.3 \%$ and $20.7 \%$ (7-13). Landmark-mark based punctures of the subclavian vein in particular were associated with increased rates of pneumothorax $(11,13-17)$. In addition, infection rates were lower for ultrasound-guided approaches with the Seldinger technique $(1.1-8.8 \%)(3,11,13,18,19)$ compared with surgical cut-down $(0.8-16.3 \%)(10,20-25)$. Moreover, the radiological technique does not require general anesthesia and is cost effective (26).

Nevertheless, fluoroscopic guidance is always associated with radiation exposure of the patient, the operator and assistant staff, but compared to other interventions, radiation exposure is comparably low (27). First studies in small populations demonstrated that the level of training has a significant influence on fluoroscopy times (FT) in several interventional procedures $(28,29)$. Moreover, while FT and dose area products (DAP) associated with other thoracic interventions, such as percutaneous coronary interventions, seem not to differ significantly based on the site of vascular access, for chest port implantations, radiation doses seem to vary depending on the access site and target vessel (30). 
The purpose of this study was to evaluate the influence of the combination of venous access site and level of experience on FT and DAP during implantation procedures for totally implantable central venous ports in a large cohort of patients.

\section{Materials and Methods}

In this retrospective, single-center study, venous port implantation procedures of 1870 consecutive patients ( 992 women, 878 men; age: $61 \pm 13.14$ years) referred by different specialists between March 2010 and April 2015 were reviewed. All patients received a Bard port system (Bard Access Systems, Salt Lake City, UT, USA). The MultiDiagnost Eleva FD2.1 (Philips Healthcare, Best, the Netherlands) fluoroscopy unit was equipped with a flat panel detector. Radiologists $(\mathrm{N}=28)$ were divided into two groups: junior $(\mathrm{N}=15)$ and senior radiological interventionalists $(\mathrm{N}=22)$ based on the number of procedures they had performed $(\leq 50$ or $>50$ ). Radiologists could therefore be part of both groups as soon as they performed their 51st procedure. The procedures performed by radiologists of both groups were analyzed with regard to FT and DAP provided by the manufacture's DAP meter. The data was saved after each procedure to our radiology information system together with the report including the access site and the name of the interventionalist.

Procedure. Access vessel patency was routinely assessed by ultrasound using a $7.5 \mathrm{MHz}$ linear array probe immediately before the procedure. At our Institution, the preferred implantation site is the right internal jugular vein due to its direct access to the superior vena cava, hence the right internal jugular vein is always used unless contraindicated.

Once the target vessel was identified, skin disinfection and sterile dressing were performed. Local anesthesia with prilocaine and epinephrine (Xylonest 1\%; AstraZeneca, Wedel, Germany) was performed at the vascular puncture site, as well at the subclavicular aspect of the ipsilateral thoracic wall. The target vessel was punctured under continuous ultrasound guidance with an 18-G needle on a syringe filled with sterile saline. Subsequently a 0.035 inch guide wire was advanced through the needle below the diaphragm to ensure venous puncture. After dilatation of the puncture tract, the needle was exchanged with a $6 \mathrm{~F}$ peel-away sheath in using the Seldinger technique.

Next, a pouch for the port reservoir was prepared $3-5 \mathrm{~cm}$ caudal of the ipsilateral clavicle. A subcutaneous tunnel was made from the reservoir to the puncture site. The $6 \mathrm{~F}$ polyurethane port catheter was advanced under fluoroscopy guidance to the caval atrial junction (approximately 2-3 $\mathrm{cm}$ below the crossing of the superior caval vein and right main bronchus) and the distal tip was connected to the port reservoir. The system was fixed to the pectoral fascia with two absorbable sutures (3-0 Vicryl, Ethicon, Norderstedt, Germany) and the skin incision sutured using a continuous intracutaneous suture. A final radiograph was then performed to ensure correct placement of the device and exclude complications such as pneumothorax (18).

Statistical analysis. This included the Shapiro-Wilk test, Spearman's correlation, Mann-Whitney $U$-test and the KruskalWallis test using SPSS Statistics (Version 23, Armonk, NY, USA). Differences with $p$-values of less than 0.05 were considered significant. Institutional Ethics Committee approval (EA4/043/15) and written informed consent were obtained.
Table I. Number of venous ports implanted by site and side. Senior $>50$ implantations; Junior $\leq 50$ implantations.

\begin{tabular}{lrr}
\hline & Right & Left \\
\hline Internal jugular vein & & \\
$\quad$ Senior & 1246 & 217 \\
$\quad$ Junior & 324 & 53 \\
Subclavian vein & & \\
$\quad$ Senior & 12 & 8 \\
Junior & 8 & 2 \\
Overall & 1590 & 280 \\
\hline
\end{tabular}

Table II. Mean and median values of the dose area product (DAP) and the fluoroscopy time (FT) according to radiologist experience.

\begin{tabular}{lcc}
\hline & DAP $\left(\mu \mathrm{Gy} \mathrm{m}^{2}\right)$ & FT $(\mathrm{s})$ \\
\hline Junior & & \\
Median & 68.2 & 0.43 \\
Mean & 131.46 & 1.30 \\
Max & 3420 & 124 \\
Min & 1.1 & 0.02 \\
Senior & & \\
Median & 57.3 & 0.24 \\
Mean & 113.19 & 2.01 \\
Max & 6099 & 452 \\
Min & 0.05 & 0.01 \\
\hline
\end{tabular}

\section{Results}

All 1870 reported venous port implantations were performed successfully without any major adverse events according to the Society of Interventional Radiology guidelines (31).

Overall, senior radiologists performed about four times more procedures than the junior subgroup during this study (Table I). Senior radiologists required significantly less FT (total median FT: Senior: $0.24 \mathrm{~s}$, Junior: $0.43 \mathrm{~s}$ ). Subgroup analysis revealed significant differences between junior and senior radiologists for right- and left-sided approaches $(p<0.001)$. Moreover, DAP was significantly lower for senior radiologists (median: Senior: $57.3 \mu \mathrm{Gy} \mathrm{m}{ }^{2}$, Junior: $68.2 \mu \mathrm{Gy} \mathrm{m}{ }^{2} ; p<0.001$ ) in comparison to junior radiologists (Figure 1, Table II). Again, subgroup analysis showed significant differences for left- $(p<0.001)$ and the rightsided approaches in both groups $(p=0.009)$.

Moreover, FT and DAP were significantly influenced by the designated target vessel $(p<0.001)$; access through the right jugular vein required the least FT and DAP (median of $0.25 \mathrm{~s}$ and $56.15 \mu \mathrm{Gy} \mathrm{m}^{2}$, respectively; Figure 2, Table III).

Furthermore, port implantations performed from the right side were associated with significant savings in terms of FT (right: $0.26 \mathrm{~s}$, left $0.40 \mathrm{~s}$ ) and DAP (right: $56.4 \mu \mathrm{Gy} \mathrm{m}{ }^{2}$, left: 

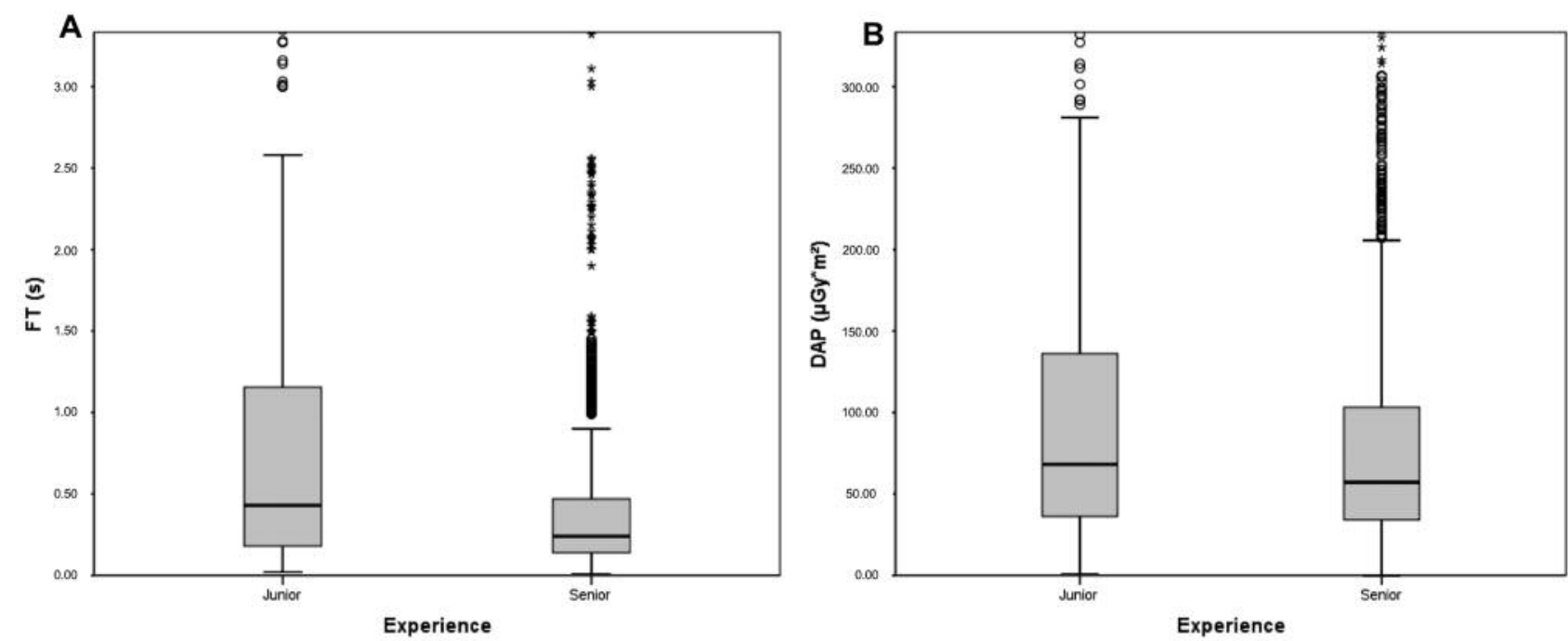

Figure 1. Fluoroscopy time (FT) (A) and dose area product (DAP) (B) according to radiologist experience. Senior $>50$ implantations; Junior $\leq 50$ implantations.
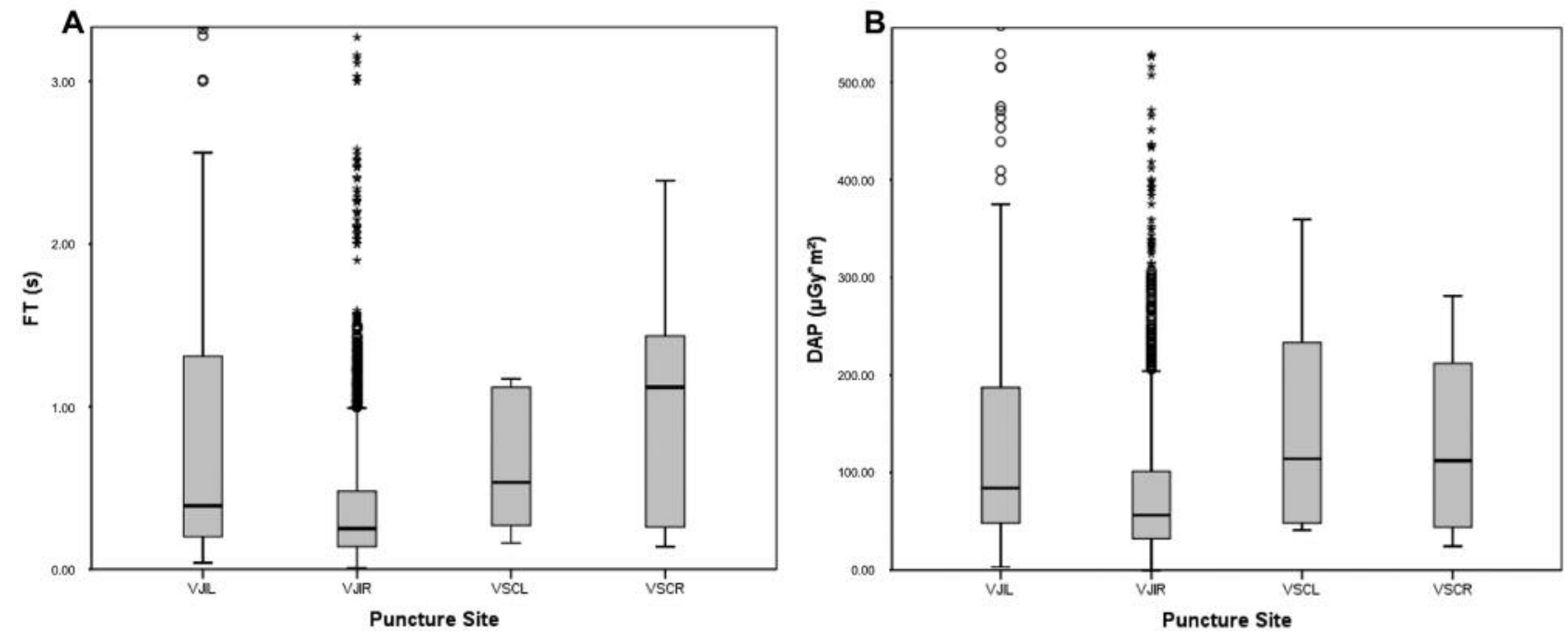

Figure 2. Fluoroscopy time (FT) (A) and dose area product (DAP) (B) according to puncture site. VJIL: Left internal jugular vein, VJIR: right internal jugular vein, VSCL: left subclavian vein, VSCR: right subclavian vein.

$85.10 \mu \mathrm{Gy} \mathrm{m}^{2}$; both $p<0.001$, Figure 3 , Table IV). There was no significant difference between the junior and senior radiologists regarding the number of right- and left-sided approaches carried out $(p=0.637)$.

\section{Discussion}

A prospective study of Bernard et al. revealed that experience of more than 50 catheterizations correlated with lower complication rates (32). Therefore, we separated our radiologists into two subgroups: junior radiologists with fewer than 50 and senior ones with more than 50 implantations.

FT and DAP should be kept as low as reasonably achievable for patient, operator and staff safety. Our study shows that right-sided puncture is correlated with lower FT and radiation doses for both junior and senior operators. Moreover, jugular access required significantly less DAP and FT than subclavian insertion of port catheters in both groups. 

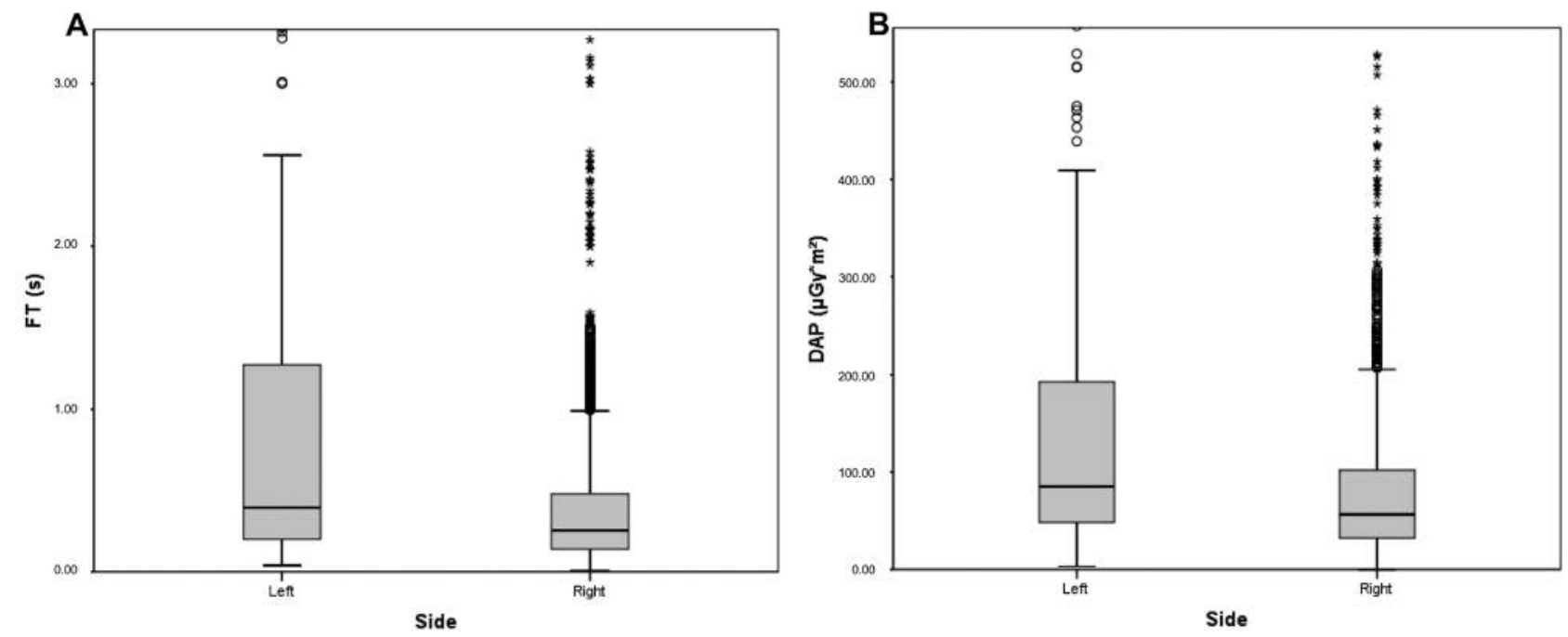

Figure 3. Fluoroscopy time (FT) (A) and dose area product $(D A P)(B)$ according to access side.

Predominantly, this might be due to the straight anatomical course to the superior vena cava reducing FT and hence the required radiation dose for correct catheter placement. These finding are in concordance with an earlier study on a smaller cohort of 138 patients by Plumhans et al. stating that jugular access reduces radiation dose by approximately $46 \%$ compared to the subclavian route. In our study, a DAP reduction of $33 \%$ was achievable for the right jugular vein compared to the mean DAP of both subclavian accesses. The left jugular vein was found to have the highest mean DAP, probably due to the curvy anatomical course. Furthermore, the right-sided approach is purported to reduce DAP by about $34 \%$ in comparison to the left (30), which is consistent with our results of a DAP reduction of $43 \%$ in a larger patient population for both subgroups.

The radiation dose depends on multiple factors, for example the fluoroscopy unit used, copper spectral beam filtration used, field of view acquired, pulse frequency and the potential number of digital subtraction angiography runs (27). The level of experience is another important factor as senior radiologists required a median $42 \%$ less FT and $16 \%$ less DAP than junior radiologists $(p<0.001)$. FT mainly serves as a surrogate parameter for intervention time, which decreases with interventionalist's experience. However, it has been shown that years in residency alone did not lead to significant reduction in FT (29).

A wide range of DAPs have been published for venous chest port implantations, for example by Plumhans et al. (subclavian: $1120 \mu \mathrm{Gy} \mathrm{m}{ }^{2}$, jugular: $513 \mu \mathrm{Gy} \mathrm{m}{ }^{2}$, left side: $1091 \mu \mathrm{Gy} \mathrm{m}{ }^{2}$,

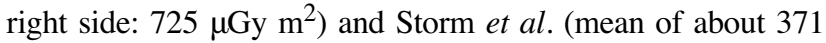
$\left.\mu \mathrm{Gy} \mathrm{m}^{2}\right)(30,33)$. The mean values in this study lie below these DAPs and under the level of deterministic radiation effects.
Table III. Fluoroscopy time $(F T)$ and dose area product (DAP) according to puncture site.

\begin{tabular}{lcccc}
\hline Measure & \multicolumn{4}{c}{ Site } \\
\cline { 2 - 5 } & VJIL & VJIR & VSCL & VSCR \\
\hline FT (s) & & & & \\
Median & 0.39 & 0.25 & 0.54 & 1.12 \\
Mean & 4.37 & 1.44 & 1.15 & 1.63 \\
Max & 452.00 & 130.00 & 6.50 & 15.34 \\
Min & 0.04 & 0.01 & 0.16 & 0.14 \\
DAP $\left(\mu G_{y} m^{2}\right)$ & & & & \\
Median & 83.90 & 56.15 & 114.10 & 112.00 \\
Mean & 186.14 & 104.31 & 148.20 & 164.98 \\
Max & 3830.00 & 6099.00 & 359.20 & 654.00 \\
Min & 3.11 & 0.05 & 40.90 & 24.30 \\
\hline
\end{tabular}

VJIL: Left internal jugular vein, VJIR: right internal jugular vein, VSCL: left subclavian vein, VSCR: right subclavian vein.

Table IV. Mean and median values of the dose area product (DAP) and fluoroscopy time (FT) according to access side.

\begin{tabular}{lrr}
\hline Measure & \multicolumn{1}{c}{ Left } & \multicolumn{1}{c}{ Right } \\
\hline FT $(\mathrm{s})$ & & \\
Median & 0.40 & 0.26 \\
Mean & 4.25 & 1.44 \\
Max & 452.00 & 130.00 \\
Min & 0.04 & 0.01 \\
DAP $\left(\mu \mathrm{Gy} \mathrm{m}^{2}\right)$ & & \\
Median & 85.10 & 56.45 \\
Mean & 184.78 & 105.07 \\
Max & 3830.00 & 6099.00 \\
Min & 3.11 & 0.05 \\
\hline
\end{tabular}


Another promising implantation technique uses ECG guidance for tip positioning. Usually a post implantation radiograph will confirm correct tip placement. Wang et al. reported no p-wave changes in about $10 \%$ of their patients, especially in left-sided approaches. Furthermore, patients with high p-waves in basal ECG-assessment tended not to show any p-wave changes during implantation. Furthermore, ECG guidance seems to be more reliable for shorter and stiff catheters due to more stable lead connections (34). Another drawback for the ECG method is its inability to differentiate between intra- and extravascular catheter position (35). On the other hand, real-time fluoroscopy guidance might be desirable in cases with anatomical variants, venous thrombosis or strictures facilitating the implantation (6).

In terms of complications, earlier studies revealed that port systems inserted through the internal jugular vein showed less dysfunction, catheter migration and catheterinduced venous thrombosis or early local infection $(7,18$, 36). Moureau et al. reported for 696.370 port catheter days a complication rate of $0.52 / 1,000$ catheter days, whereas infections were described in $0.30 / 1,000$ catheter days and dysfunctions in $0.21 / 1,000$ catheter days (37). The risk of thrombosis is higher if the port system is inserted through the subclavian vein compared to the internal jugular vein $(38,39)$. Furthermore, the stenosis rate is lower with insertion in the jugular vein due to its large diameter and high blood flow (40). Ultrasound-guided puncture of the internal jugular vein reduces the risk of arterial puncture, hematoma and pneumothorax compared to the subclavian approach (41). The risk of the pinch-off syndrome, a mechanical stress on the catheter compressed between the first rib and the clavicle, is nil in using jugular access and could be increased using a very lateral puncture site in subclavian approaches. This can be avoided by jugular access (42). Hence, the right jugular vein appears to be the best target vessel for prevention of catheter-related complications.

This study is limited due to its retrospective design. Further prospective studies should include additional dose measurements with patient radiation dosimeter so that effective doses can be calculated.

In conclusion, because of significant DAP and FT reductions associated with right-sided approaches and jugular access routes, we suggest that the right jugular vein is the most favorable implantation side for totally inserted venous port systems.

For further dose reduction and increase in safety of patients and staff, residents should be well-trained.

\section{Acknowledgements}

Dr. Martin Jonczyk and Dr. Federico Collettini participate in the BIH-Charité Clinical Scientist Program funded by the Charite Universitätsmedizin Berlin and the Berlin Institute of Health.

\section{References}

1 Viana Taveira MR, Lima LS, de Araujo CC and de Mello MJ: Risk factors for central line-associated bloodstream infection in pediatric oncology patients with a totally implantable venous access port: A cohort study. Pediatr Blood Cancer 64(2): 336-342, 2017.

2 Goltz JP, Noack C, Petritsch B, Kirchner J, Hahn D and Kickuth $\mathrm{R}$ : Totally implantable venous power ports of the forearm and the chest: Initial clinical experience with port devices approved for high-pressure injections. Br J Radiol 85(1019): e966-972, 2012.

3 Gebauer B, El-Sheik M, Vogt M and Wagner H-J: Combined ultrasound and fluoroscopy guided port catheter implantation high success and low complication rate. European Journal of Radiology 69(3): 517-522, 2009.

4 Niederhuber JE, Ensminger W, Gyves JW, Liepman M, Doan K and Cozzi E: Totally implanted venous and arterial access system to replace external catheters in cancer treatment. Surgery 92(4): 706-712, 1982.

5 Morris SL, Jaques PF and Mauro MA: Radiology-assisted placement of implantable subcutaneous infusion ports for longterm venous access. Radiology 184(1): 149-151, 1992.

6 Gebauer B: Venöse zugänge - implantation und komplikationsmanagement. Interventionelle Radiologie Scan 03(01): 51-73, 2015.

7 Teichgraber UK, Kausche S, Nagel SN and Gebauer B: Outcome analysis in 3,160 implantations of radiologically guided placements of totally implantable central venous port systems. Eur Radiol 21(6): 1224-1232, 2011.

8 Chen PT, Sung CS, Wang CC, Chan KH, Chang WK and Hsu WH: Experience of anesthesiologists with percutaneous nonangiographic venous access. J Clin Anesth 19(8): 609-615, 2007.

9 Caers J, Fontaine C, Vinh-Hung V, De Mey J, Ponnet G, Oost C, Lamote J, De Greve J, Van Camp B and Lacor P: Catheter tip position as a risk factor for thrombosis associated with the use of subcutaneous infusion ports. Support Care Cancer 13(5): 325-331, 2005.

10 Biffi R, Orsi F, Pozzi S, Pace U, Bonomo G, Monfardini L, Della Vigna P, Rotmensz N, Radice D, Zampino MG, Fazio N, de Braud F, Andreoni B and Goldhirsch A: Best choice of central venous insertion site for the prevention of catheter-related complications in adult patients who need cancer therapy: A randomized trial. Ann Oncol 20(5): 935-940, 2009.

11 Lorch H, Zwaan M, Kagel C and Weiss HD: Central venous access ports placed by interventional radiologists: Experience with 125 consecutive patients. Cardiovasc Intervent Radiol 24(3): 180-184, 2001.

12 Shetty PC, Mody MK, Kastan DJ, Sharma RP, Burke MW, Venugopal C and Burke TH: Outcome of 350 implanted chest ports placed by interventional radiologists. J Vasc Interv Radiol 8(6): 991-995, 1997.

13 Vardy J, Engelhardt K, Cox K, Jacquet J, McDade A, Boyer M, Beale P, Stockler M, Loneragan R, Dennien B, Waugh R and Clarke SJ: Long-term outcome of radiological-guided insertion of implanted central venous access port devices (cvapd) for the delivery of chemotherapy in cancer patients: Institutional experience and review of the literature. Br J Cancer 91(6): 1045-1049, 2004.

14 Araujo C, Silva JP, Antunes P, Fernandes JM, Dias C, Pereira H, Dias T and Fougo JL: A comparative study between two central veins for the introduction of totally implantable venous access devices in 1201 cancer patients. Eur J Surg Oncol 34(2): 222$226,2008$. 
15 Biffi R, Pozzi S, Agazzi A, Pace U, Floridi A, Cenciarelli S, Peveri V, Cocquio A, Andreoni B and Martinelli G: Use of totally implantable central venous access ports for high-dose chemotherapy and peripheral blood stem cell transplantation: Results of a monocentre series of 376 patients. Ann Oncol 15(2): 296-300, 2004.

16 Vandoni RE, Guerra A, Sanna P, Bogen M, Cavalli F and Gertsch P: Randomised comparison of complications from three different permanent central venous access systems. Swiss Med Wkly 139(21-22): 313-316, 2009.

17 Biffi R, De Braud F, Orsi F, Pozzi S, Arnaldi P, Goldhirsch A, Rotmensz N, Robertson C, Bellomi M and Andreoni B: A randomized, prospective trial of central venous ports connected to standard open-ended or groshong catheters in adult oncology patients. Cancer 92(5): 1204-1212, 2001.

18 Wagner HJ, Teichgraber U, Gebauer B and Kalinowski M: Transjugular implantation of venous port catheter systems. Rofo 175(11): 1539-1544, 2003.

19 Funaki B, Szymski GX, Hackworth CA, Rosenblum JD, Burke $\mathrm{R}$, Chang T and Leef JA: Radiologic placement of subcutaneous infusion chest ports for long-term central venous access. AJR Am J Roentgenol 169(5): 1431-1434, 1997.

20 Stein $\mathrm{M}$ and Wagner RH: Complications of central venous access devices: Outcome analysis of 2359 implantations. Dtsch Med Wochenschr 130(18): 1129-1132, 2005.

21 Ignatov A, Hoffman O, Smith B, Fahlke J, Peters B, Bischoff J and Costa SD: An 11-year retrospective study of totally implanted central venous access ports: Complications and patient satisfaction. Eur J Surg Oncol 35(3): 241-246, 2009.

22 Samaras P, Dold S, Braun J, Kestenholz P, Breitenstein S, Imhof A, Renner C, Stenner-Liewen F and Pestalozzi BC: Infectious port complications are more frequent in younger patients with hematologic malignancies than in solid tumor patients. Oncology 74(3-4): 237-244, 2008.

23 Wolosker N, Yazbek G, Nishinari K, Malavolta LC, Munia MA, Langer $\mathrm{M}$ and Zerati AE: Totally implantable venous catheters for chemotherapy: Experience in 500 patients. Sao Paulo Med J 122(4): 147-151, 2004.

24 Hartkamp A, van Boxtel AJ, Zonnenberg BA and Witteveen PO: Totally implantable venous access devices: Evaluation of complications and a prospective comparative study of two different port systems. Neth J Med 57(6): 215-223, 2000.

25 Hsieh CC, Weng HH, Huang WS, Wang WK, Kao CL, Lu MS and Wang CS: Analysis of risk factors for central venous port failure in cancer patients. World J Gastroenterol 15(37): 4709-4714, 2009.

26 LaRoy JR, White SB, Jayakrishnan T, Dybul S, Ungerer D, Turaga $\mathrm{K}$ and Patel PJ: Cost and morbidity analysis of chest port insertion: Interventional radiology suite versus operating room. J Am Coll Radiol 12(6): 563-571, 2015.

27 Schueler BA, Vrieze TJ, Bjarnason H and Stanson AW: An investigation of operator exposure in interventional radiology. Radiographics 26(5): 1533-1541, 2006.

28 Lim R, Khawaja RD, Nimkin K, Sagar P, Shailam R, Gee MS and Westra SJ: Relationship between radiologist training level and fluoroscopy time for voiding cystourethrography. AJR Am J Roentgenol 200(3): 645-651, 2013.

29 Xu BJ, Duszak R Jr., McGinnis RS, Stanfill JG, O'Rear J and An AQ: Increased fluoroscopy time for central venous catheter placement by radiology residents versus staff radiologists. J Am Coll Radiol 10(7): 518-522, 2013.
30 Plumhans C, Mahnken AH, Ocklenburg C, Keil S, Behrendt FF, Gunther RW and Schoth F: Jugular versus subclavian totally implantable access ports: Catheter position, complications and intrainterventional pain perception. Eur J Radiol 79(3): 338-342, 2011.

31 Sacks D, McClenny TE, Cardella JF and Lewis CA: Society of interventional radiology clinical practice guidelines. J Vasc Interv Radiol 14(9 Pt 2): S199-202, 2003.

32 Bernard RW and Stahl WM: Subclavian vein catheterizations: A prospective study. I. Non-infectious complications. Ann Surg 173(2): 184-190, 1971.

33 Storm ES, Miller DL, Hoover LJ, Georgia JD and Bivens T: Radiation doses from venous access procedures. Radiology 238(3): 1044-1050, 2006

34 Wang G, Guo L, Jiang B, Huang M, Zhang J and Qin Y: Factors influencing intracavitary electrocardiographic p-wave changes during central venous catheter placement. PLoS One 10(4): e0124846, 2015.

35 Schummer W, Schummer C, Paxian M, Stock U, Richter K and Bauer M: Extravasal position of central venous catheters despite unsuspicious ecg-guidance. Anasthesiol Intensivmed Notfallmed Schmerzther 40(2): 91-96, 2005.

36 Yip D and Funaki B: Subcutaneous chest ports via the internal jugular vein. A retrospective study of 117 oncology patients. Acta Radiol 43(4): 371-375, 2002.

37 Moureau N, Poole S, Murdock MA, Gray SM and Semba CP: Central venous catheters in home infusion care: Outcomes analysis in 50,470 patients. J Vasc Interv Radiol 13(10): 10091016, 2002.

38 Ma LI, Liu Y, Wang J, Chang Y, Yu L and Geng C: Totally implantable venous access port systems and associated complications: A single-institution retrospective analysis of 2,996 breast cancer patients. Mol Clin Oncol 4(3): 456-460, 2016.

39 Lee SH and Hahn ST: Comparison of complications between transjugular and axillosubclavian approach for placement of tunneled, central venous catheters in patients with hematological malignancy: A prospective study. Eur Radiol 15(6): 1100-1104, 2005.

40 Teichgraber UK, Gebauer B, Benter T and Wagner J: Long-term central venous lines and their complications. Rofo 176(7): 944952, 2004.

41 Tsotsolis N, Tsirgogianni K, Kioumis I, Pitsiou G, Baka S, Papaiwannou A, Karavergou A, Rapti A, Trakada G, Katsikogiannis N, Tsakiridis K, Karapantzos I, Karapantzou C, Barbetakis N, Zissimopoulos A, Kuhajda I, Andjelkovic D, Zarogoulidis K and Zarogoulidis P: Pneumothorax as a complication of central venous catheter insertion. Ann Transl Med 3(3): 40, 2015.

42 Jordan K, Behlendorf T, Surov A, Kegel T, Maher G and Wolf HH: Venous access ports: Frequency and management of complications in oncology patients. Onkologie 31(7): 404-410, 2008. 